\title{
Research On The Implementation Of Online Monitoring SS Series Locomotive Braking And Wheel Ovalization
}

\author{
Yan Jun \\ Hunan Railway Professional technology College, Zhu Zhou ,412001,China \\ E-mail:923432562@qq.com
}

\begin{abstract}
Keywords: braking condition, wheel ovalization, displacement sensors, brake shoe wear, tire wear Abstract: This paper studies online monitoring of SS series locomotive braking and wheel ovalization. Two displacement sensors were used to detect real-time displacement amount of brake actuator and tire tread, which were calculated by IPC for real-time monitoring of braking remission, braking, brake shoe wear, tire wear and wheel ovalization. This paper aims to timely solve the problems of poor braking, ensuring traffic safety. MATLAB software simulated the changing curve of ovalization and verified the feasibility of on-line monitoring of wheel ovalization.
\end{abstract}

\section{Introduction}

Brake system plays an important role in ensuring rail transport safety. At present, the brake system of China SS series locomotive uses independent box-type unit brake. It is a basic cabinet-type braking device, with brake cylinders, brake actuator and brake shoe clearance adjustor mounted in the cabinet, and brake shoe installed outside of cabinet. The breaking process is implemented in the inflated cylinder, when a piston rod which is driven by piston makes brake shoe mechanically rub on the surface of wheel tread. When the brake cylinder is exhausted, the piston rod is pulled by spring ease, and the brake shoe left away from tread because of brake remission [1].

The brake shoe, mostly made of cast iron, needs to be replaced owing to frequent braking and serious friction. Otherwise there will be braking failure. The mitigating of brake actuator is pushed by spring, and a frequent use then will cause mechanical fatigue. If mitigation is not to be relieved in place, it will result in bonding between brake shoe and tread. A long braking state of this, if not timely alleviated, will make the wheel temperature rise and tire sluggish, resulting in a rollover accident. With wheel becoming ovalized, the vehicle systems will be seriously deteriorated in lateral stability, and wheel load reduction rate will be greatly reduced, thereby reducing life of each component in the vehicle / track system, or even causing derailment risk [2].

This paper put forward an on-line system of monitoring wheel braking condition and wheel ovalization. It hopes to solve the problem in monitoring the working condition of brake unit, remission state, shoe and tire wear and ovalization, thus to safeguard the locomotive operation.

\section{System design}

The system used two displacement sensors in two places to detect each parameter. Those parameters, including mechanical change signals produced by sensor, train speed and braking signal, then were transmitted to the central processing unit for the calculation of the thickness of the brake, wear degree of wheel on tread, degree of wheel ovalization, level of brake remission in place. If the data exceeded the set parameter, the drive sound and light alarms prompted the operator. Figure 1 is a 
schematic block diagram.

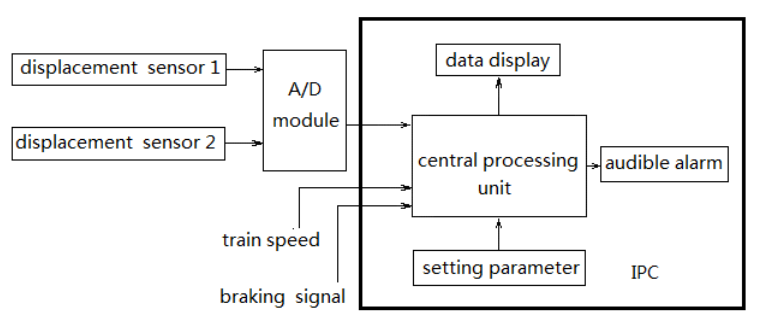

Figure 1: Block diagram of Online Monitoring

In this study, the IPC consisted of a central processing unit, a dedicated A / D module and a movable lever resistance displacement sensor of $4 \sim 20 \mathrm{~mA}$ in output signal current [3] which is large enough not to be affected by the locomotive running or long-distance transmission.

On the man-machine interface, we can set the initial place of the displacement sensor as the initial point of brake ease in place according to its installation. In the initial position (no brake shoe wear, brake mitigated in place, and no tread wear) the gap from wheel to tire tread is $\delta$. If brake remission reset deviated, and if the deviation was too large (the operator can set the displacement on request according to the itinerary), IPC audible alarm would show pilot or maintenance personnel that mitigation is not in place and failure needs to be dealt with.

\section{The implementation of detecting braking condition}

\section{Detection and calculation of shoe and wheel tire tread clearance}

The "fixed house" of displacement sensor1 is installed on the brake unit cabinet, and the detection head of the displacement sensor is attached to the connecting shaft of brake lever and head. When brake works, detecting head of sensor 1 will move with the driving force from brake head. In the initial case (no brake shoe wear, brake mitigated in place, and no tread wear) the length from the fixed end of sensor to detecting head is X10. Under the situation that the brake shoe and tread are worn, and brake is alleviated in place, the length from fixed end of sensor to detecting head is $\mathrm{X} 1$.The start position of brake remission will change again due to resetting of braking remission, whose amount $\Delta \mathrm{X} 10$ was shown in Fig 2. By using equation (1) we can obtain:

$$
\Delta X_{10}=X_{1}-X_{10}
$$

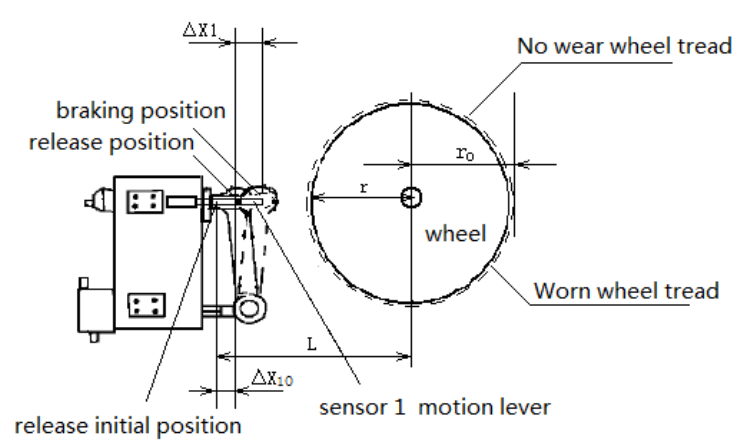

Figure 2: The detection and parameter schematic of the gap from brake shoe to tread

The train speed and braking signal are read out in IPC when the train slows down and the train brakes. In braking, the length from the fixed end senor 1 to detecting head X2 is recorded. The wheel tread shoe clearance $\Delta \mathrm{X} 1$ can be obtained by equation (2). 


$$
X_{2}-X_{1}=\Delta X_{1}
$$

\section{Detection and calculation of wheel on tread wear and ovalization}

The "fixed house" of displacement sensor 2 was located on the connecting shaft of brake lever and brake head. The head of displacement sensor 2 was self-healing, which was at the initial position if there was no mechanical collision, and the length from fixed end to the sensor head was at its extreme. If there was mechanical collision, the moving rod then retracted and displaced, as shown in Figure 3.

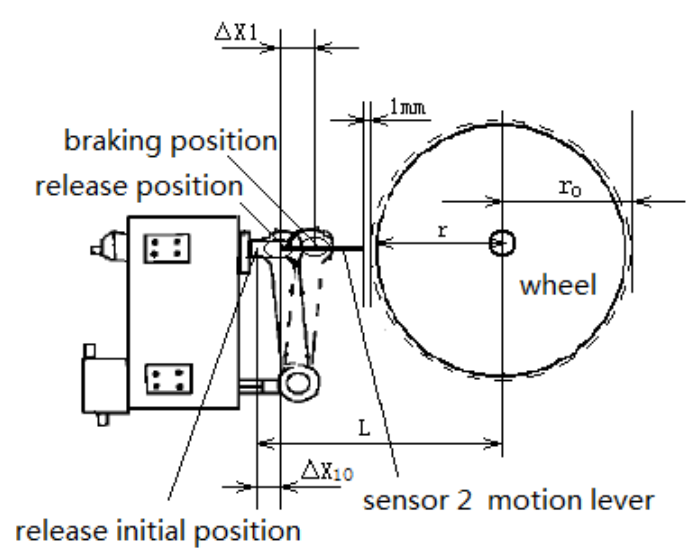

Figure 3: Parameters of detecting and calculating wear of wheel on tread

The length from fixed end to the detecting head was X2 when there was no mechanical collision on displacement sensor 2. A gap (it is changeable when installing the fixed house) of $1 \mathrm{~mm}$ was reserved when brake relives and level of displacement sensor 2 doesn't contact with the unworn wheel tread. Here $\mathrm{r} 0$ was the radius of unworn wheel, $\mathrm{r}$ being worn one, and $\Delta \mathrm{r}$ a wear size; $\mathrm{L}$ was the length from initial remission position to wheel center. When it braked, the movement of detecting head to wheel was extruded by tread, and this head retracting produced displacement $\Delta \mathrm{X} 2 . \Delta \mathrm{r}$, the wear of wheel on tread, can be deduced by using following equation.

$$
\begin{gathered}
\Delta r=r_{0}-r \\
L-r_{0}-X_{2}=1 \\
L-r-\Delta X_{10}=X_{2}-\Delta X_{2}
\end{gathered}
$$

$\Delta \mathrm{r}$ can be deduced through above formula:

$$
\Delta r=\Delta X_{2}-\Delta X_{10}+1
$$

The result, namely, wear size of wheel on tread, will be displayed on the man-machine interface, which requires the driver or maintenance personnel to give a timely treatment.

$\Delta \mathrm{r}$ was a time-varying function $\Delta \mathrm{r}(\mathrm{t})$ when wheel became ovalized, namely:

$$
\Delta r(t)=\Delta X_{2}(t)-\Delta X_{10}+1
$$




\section{Detection and calculation of brake shoe wear}

Brake shoe wear can be calculated out through appropriate detecting data which were all shown in Figure 4. L1 was the measurement from connection shaft to outside edge of brake shoe (a lamination position of wheel onto tread).

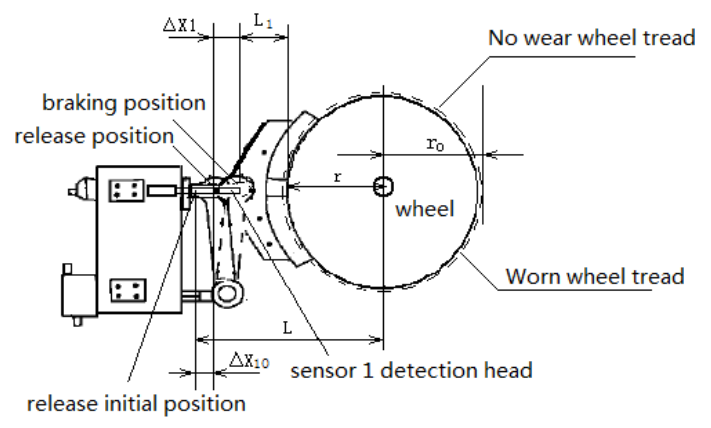

Figure 4: Parameters of detecting brake shoe wear

The thickness of the brake shoe wear $\Delta \mathrm{h}$ was deduced by the following formula.

$$
\begin{gathered}
L=L_{1}+\Delta h+\delta+r_{0} \\
L=\Delta X_{10}+\Delta X_{1}+L_{1}+r
\end{gathered}
$$

The formula above can further deduce:

$$
\Delta h=2 \Delta X_{10}+\Delta X_{1}-\Delta X_{2}-\delta-1
$$

Above parameters of $\mathrm{L}, \mathrm{r} 0, \mathrm{~L} 1$, initial brake remission position were set into the IPC on touch screen of man-machine interface.

\section{Simulation of detecting wheel ovalization}

By referring corresponding literature [4], to process the question of unrounded wheels, this study adopts a method of calculating long-wave and long-periodic non-circularization wheel, and thus creating a mathematical oval wheels model. The wheel radius here was a function of time $\mathrm{r}(\mathrm{t})[4]$ :

$$
r(t)=\frac{a b}{\sqrt{a^{2} \sin ^{2} \theta(t)+b^{2} \cos ^{2} \theta(t)}}
$$

Wherein, a, b represented the minor and axis length of oval wheels respectively. $\theta(t)$ was an initial nominal contact angle between the radius of oval wheel and its horizontal axis at the time $\mathrm{t}$, as it shown in Figure 5. Formula (12) below carried out the calculation.

$$
\theta(t)=\theta(t-1)+\omega \Delta t
$$

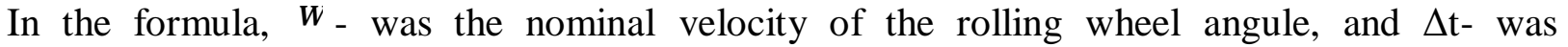
integration time step.

Formula (11), (12) and Figure 5 showed the wheel oval model, with both ends of the oval wheel on the process being often asymmetrical. It assumed that the ovalization process of the two wheels was asymmetrical, i.e. two elliptical phase difference was $\Phi$, which was showed in Figure 6 [4]. 


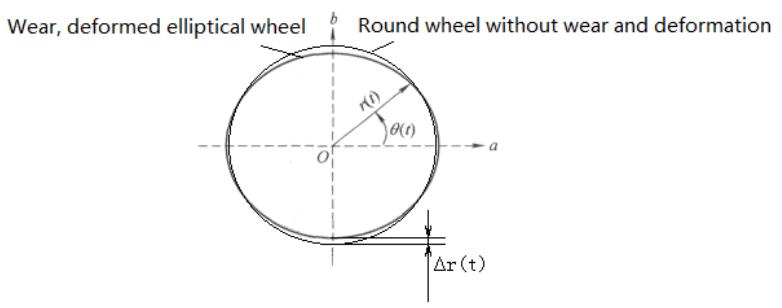

Figure 5: Calculation model of elliptical wheel

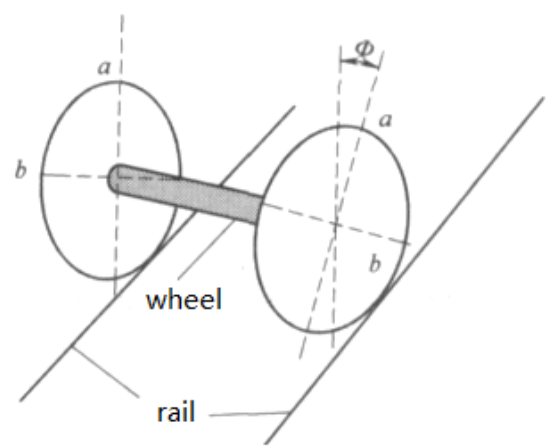

Figure 6: Angle phase of elliptical wheel

A mathematical model was based on equation (11) and (12), with a, b and $\Phi$ being assigned as the value of $624.5,619.5$ and $6^{\circ}$. Standard radius and speed of electric locomotive wheel were 625 $\mathrm{mm}$ and $100 \mathrm{Km} / \mathrm{h}$. MATLAB software simulated the relationship between wheels ellipse degree and $\Delta \mathrm{r}(\mathrm{t})$, whose change reflected the wheels ovalization degree. Simulation graph was showed in Figure 7.

The curves 1 and 2 represented the left and right wheel curve $\Delta \mathrm{r}(\mathrm{t})$ respectively. The curve wave peak and valley value manifested the differences of the minor axis $(0.5 \mathrm{~mm})$ and long axis $(5.5 \mathrm{~mm})$ with the standard wheel.

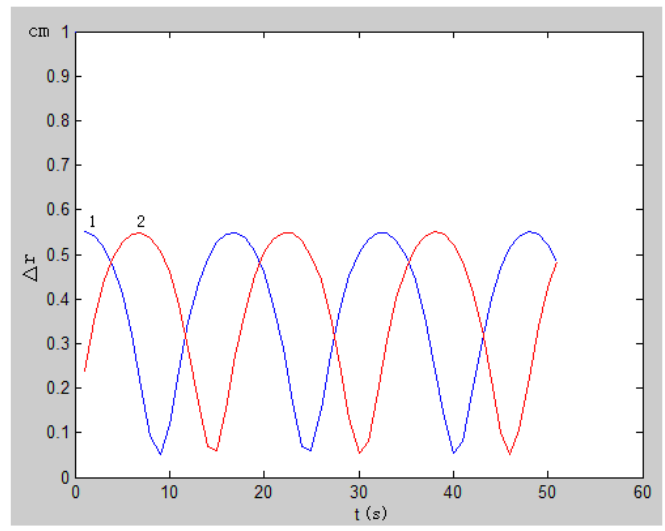

Figure 7: Simulation graph

When system operated, the data would be collected and stored in real time into IPC as a basis for detecting wheels online; the maximum and minimum value and the phase difference of the ovaliztion was reflected in IPC interface. It prompted the operator that there was a phase angle turn on two wheels, if reached the set threshold extent, the sound and light alarm would be started. 


\section{Conclusions}

The design adopted a displacement sensor, which was easy in installation, not so strict and difficult in size and installation, thus better for mass production.

The sensor converted displacement into a current signal, a very good way to control other interferences. The signal acquisition and operation by two displacement sensors really detected wheel tread wear and ovalization degree, shoe thickness and brake remission. Hopefully, it can help the staff promptly replace the wheel, brake shoe and overhaul brake, so as to avoid traffic accidents caused by such failures.

\section{References}

[1] Li Yimin, Electric locomotive brake [M] Beijing: China Railway Publishing House, 2008.8.

[2] Zhang Xueshan, Xiao xin-biao, Jin Xue-song, On the affection the wheel ovalization on the vehicle speed system [J] Mechanical Engineering, 2010, 46 (16): 67-73.

[3] Song Xuechen, Sensor and detecting technology [M]. Beijing: people's posts and telecommunications press, 2009.5.

[4] Zhang Xueshan, Xiao Xin-biao, Jin Xue-song, High speed wheel with elliptic problem and its impact on the vehicle's lateral stability [J] Journal of mechanical engineering, 2010,46 (16): 67-73.

\section{The author}

Yan Jun(1976-), male, Xuanhan, Sichuan, associate Professor / Senior Engineer; Research direction: power electronic technology and automatic control technology.

This work is supported by 2015 Year Of The Hunan Provincial Department Of Education Scientific Research Of The Youth Special: Research and development of on-line monitoring system for train brake and wheel (Number: 15B155) 